\title{
Xanthomatous Lesion of the Gingiva: A possible cause of delayed tooth eruption
}

\author{
Hiroko Ida-Yonemochi ${ }^{1}$, Tadashi Noda ${ }^{2}$, Yukiko Ono ${ }^{3}$, and Takashi Saku ${ }^{1}$ \\ Departments of ${ }^{1}$ Pathology, ${ }^{2}$ Pedodontics and ${ }^{3}$ Oral and Maxillofacial Surgery, Niigata University School of Dentistry, Niigata, Japan
}

Ida-Yonemochi H, Noda T, Ono Y, and Saku T. Xanthomatous lesion of the gingiva: a possible cause of delayed tooth eruption. Oral Med Pathol 1999; 4: 79 84, ISSN 1342-0984.

\begin{abstract}
The authors report the rare case of a granular cell lesion of the gingiva overlying a maxillary incisor tooth that was delayed in eruption in a 9-year-old Japanese boy. The lesion was composed of a nodular aggregation of ovoid-shaped cells with eosinophilic and granular cytoplasm, which was immunohistochemically positive for LDL, CD68, HLA-DR, cathepsin D and heparanase. These cells were neither positive for S-100 protein, vimentin, desmin nor myosin. The results suggested that this lesion is a sort of xanthoma, but neither granular cell tumor nor congenital epulis. The etiology of this lesion is unknown, but it seems to be associated with tissue remodeling processes of the pericoronal mesenchymal tissue during tooth eruption. Such an unusual pericoronal tissue containing a xanthomatous lesion may be one of the causes for delay in tooth eruption.
\end{abstract}

Key words: xanthomatous lesion, delayed tooth eruption, gingiva, immunohistochemistry

Correspondence: Takashi Saku, Department of Pathology, Niigata University School of Dentistry, 2-5274 Gakkocho-dori, Niigata, 951-8514, Japan

Phone: (+81) 25 227-2832 Facsimile: (+81) 252270805

E-mail: tsaku@dent.niigata-u.ac.jp

\section{Introduction}

Delayed eruption of permanent incisor teeth in the maxilla is usually caused by such local factors as early loss, persistence of deciduous teeth, trauma, inflammation, supernumerary teeth, cysts and tumors, which are mostly associated with precedent deciduous teeth. However, the cause of retarded eruption of molar teeth is rather controversial, except in patients with systemic backgrounds. To date, there have been only a few reports in which the histology of the operculum of permanent teeth delayed in eruption was analyzed (1-3). Philipsen et al. histologically examined tissue specimens of gingiva overlying molar teeth delayed in eruption and found that the existence of odontogenic giant cell fibromatosis (OGCF) in the opercula caused the retarded molar tooth eruption (2). In the previous study, we examined histopathology of sixty-one operculum specimens from the patients with incisor or molar teeth delayed in eruption, and showed that there were two histological varieties: pericoronal myxofibrous hyperplasia $(\mathrm{PMH})$ and infantile ameloblastic fibromatosis (IAF) in the opercula. $\mathrm{PMH}$ is a disease entity which includes more varied pericoronal hamartomatous lesions than OGCF and affects not only molars but also incisors. We have considered that such pericoronal hamartomas induce fibrosis in the lamina propria of the gingival mucosa, which might disturb some erup- tion processes of teeth (3).

In this article, we report a case of a solitary granular cell nodule occurring in the overlying gingiva of an incisor tooth delayed in eruption. Since such a histological variant was not listed in our previous series of pericoronal lesions, we studied the nature of the constituent cells of the nodule by using immunohistochemical techniques and discussed the possible cause of delayed tooth eruption.

\section{Case Report}

A 9-year-old Japanese boy was referred to the pedodontic unit of Niigata University Dental Hospital for delayed eruption of the left central incisor in his maxilla. One year and 5 months before, his deciduous incisor was extracted due to persistence. However, the succeeding incisor had not yet erupted. The overlying mucosa appeared normal and the right counterpart incisor had erupted completely. He had a history of extraction of an impacted median supernumerary tooth of the maxilla three years before in this hospital. The mesiodens was located between two central incisor tooth germs, but its extraction surgery from the palatal side did not touch the operculum areas of the central incisors. There was no familial or personal history of other diseases, and the patient's general health and development were within normal ranges. 
The radiographic examination revealed nothing of note around the crown of the unerupted incisor, whose root formation appeared to be almost the same as its counterpart. Clinically, the cause for delayed eruption of the incisor was not clear.

The operculum was surgically removed and the tissue was submitted to histopathologic examination. The postoperative course was uneventful. Two months later, eruption of the left central incisor was confirmed and it was in line with the right incisor.

\section{Materials and Methods}

The surgical specimen was fixed in $10 \%$ formalin and was embedded in paraffin, and serial sections were cut at $4 \mu \mathrm{m}$ and stained with hematoxylin-eosin (H-E), periodic acid-Schiff (PAS) with or without diastase digestion, Masson's trichrome, toluidine blue and silver impregnation. Sections were also used for immunoperoxidase stainings for CD68, HLA-DR, heparanase, cathepsin D, S-100 protein, vimentin, desmin, myosin, low density lipoprotein (LDL), and type IV collagen. Furthermore, unstained sections were examined with ultraviolet light for fluorescence by ceroid under a phase-contrast microscope equipped with epifluorescence optics (Olympus BH2, DM400 dichroic mirror with a $334 \mathrm{~nm}$ excitation filter, Tokyo).

Table 1: Antibodies used in this study

\begin{tabular}{lll}
\hline Antibody & Clone & Source \\
\hline CD68 & PG-M 1 & Dako \\
HLA-DR & CR 3/43 & Dako \\
vimentin & V 9 & Nichirei \\
desmin & monoclonal & Labsystems \\
heparanase & monoclonal & Toyoshima M et al. ${ }^{(4)}$ \\
S-100 & polyclonal & Nichirei \\
cathepsin D & polyclonal & Saku T et al.${ }^{(5)}$ \\
LDL (apo B) & polyclonal & Biogenesis \\
type IV collage & polyclonal & Cheng J et al..$^{(6)}$ \\
myosin & polyclonal & Saku T et al..${ }^{(7)}$ \\
\hline
\end{tabular}

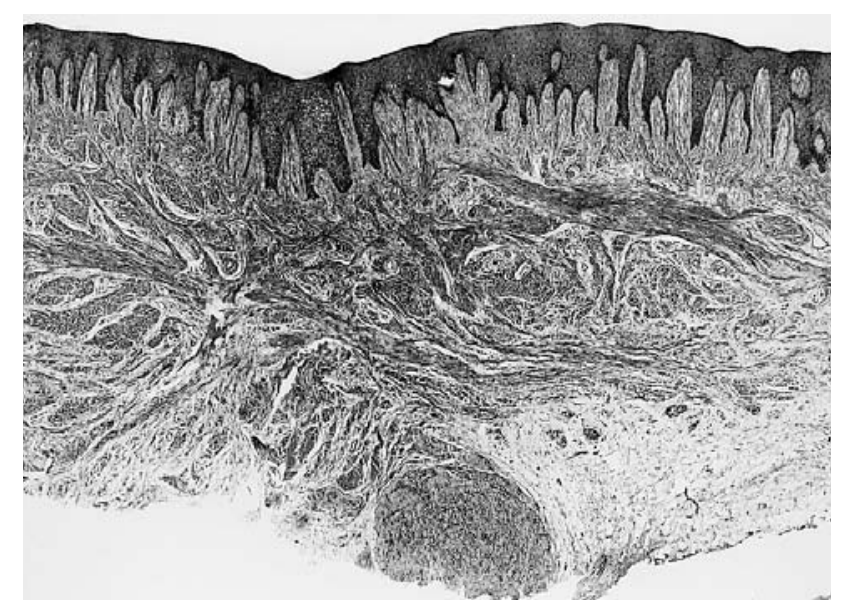

Fig. 1: Histology of the gingival operculum tissue. In the deep portion of the lamina propria, there is a nodular aggregation of granular cells. Myxoid change of the stroma is noticeable around the nodule (H-E stain, $\times 25)$.
Immunohistochemical studies were performed using the avidin-biotin peroxidase complex (ABC) method with the mouse monoclonal antibodies to CD68, HLA-DR, vimentin and desmin, and the rabbit monoclonal antibody to heparanase (4) (provided by Dr. M. Nakajima, Novartis Pharma International Institute, Takarazuka, Japan). A peroxidase-antiperoxidase (PAP) technique was also employed for the rabbit polyclonal antibodies to S-100 protein, cathepsin D (5), LDL (apo B) and type IV collagen (6) as described previously. Polyclonal antibodies against smooth and skeletal muscle myosins were raised in rabbit as described elsewhere (7). Antibodies used in this study are listed in Table 1.

\section{Pathological Findings}

The overlying gingival mucosa of the operculum showed reactive hyperplasia of the epithelium and a thick layer of fibrosis in the lamina propria. In the submucosal layer, there was a nodular aggregation of granular cells surrounded by myxoid stroma, which seemed to be of odontogenic origin, showing no hyperplastic changes (Fig. 1). These granular cells were round to polygonal in shape and had eosinophilic and granular cytoplasm. Their nuclei were rather small and round-shaped and eccentrically located (Fig. 2). The cytoplasm was PAS positive (Fig. 3a) even after diastase treatment. With Masson's trichrome stain, the granules stained reddishbrown (Fig. 3b). The nodule was separated by argyrophilic fibers into indefinite lobular structures (Fig. 3c). However, there was no obvious capsule around it. Much smaller nests of similar granular cells were scattered in the surrounding connective tissue (Fig. 4a). The cytoplasmic granules of these granular cells showed immunopositive for LDL-apo B (Fig. 4b) and also exhibited yellow fluorescence with ultraviolet excitation (Fig. 4c). There was no infiltration of inflammatory cells within or around the granular cell nodules.

Immunohistochemically, the granular cells showed

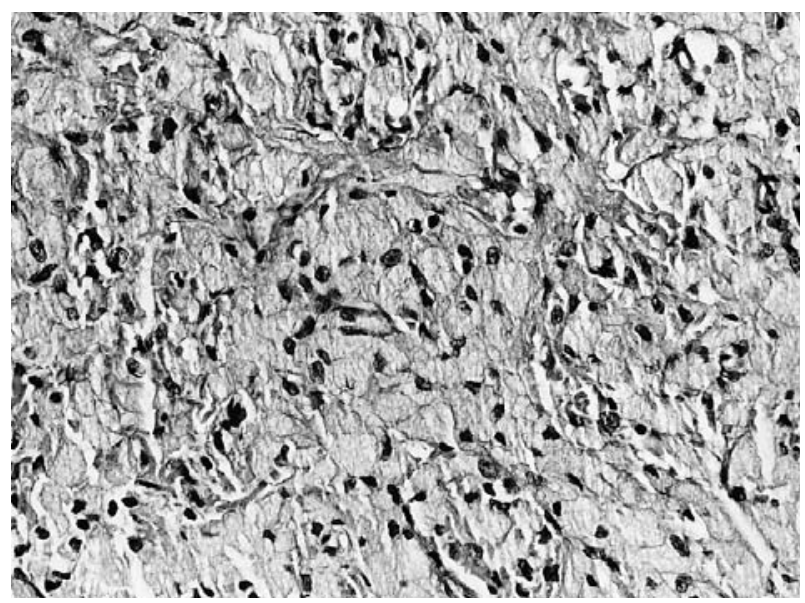

Fig. 2: High power appearance of the granular cell nodule. Granular cells are round to polygonal in shape and have eosinophilic and granular cytoplasm. Round nuclei are located in periphery (H-E stain, $\times 380)$. 

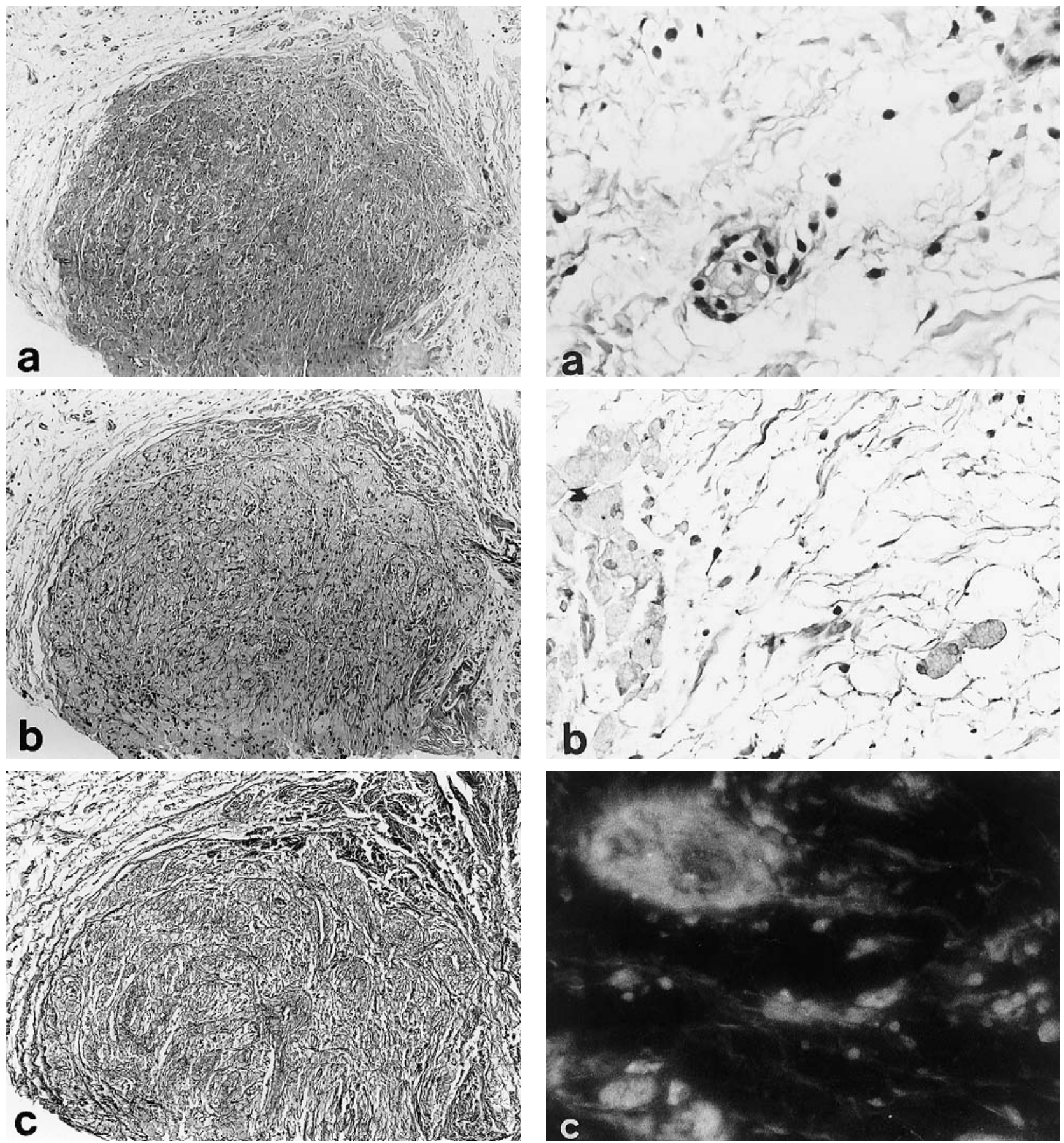

Fig. 3: Histologic features of granular cells. The cytoplasm is PAS positive and diastase resistant, and their granules stain reddish-brown with Masson's trichrome. There is no apparent alveolar arrangement of granular cells (a, periodic acid-Schiff (PAS), b, Masson's trichrome, c, silver impregnation, $\times 125$ ).

strong and finely granular stainings for CD68 (Fig. 5a) and HLA-DR (Fig. 5b) and coarsely granular for cathep$\sin \mathrm{D}$ (Fig. 5c) in the cytoplasm. They also displayed a weakly positive reaction for heparanase (data not shown), whereas they were not positive in the reactions with the antibodies against S-100 protein, vimentin, desmin and myosin. These immunohistochemical results of granular cell were summarized in Table 2. Futhermore, the nodule was rich in blood vessels, as was revealed by anti-type IV collagen (Fig. 5d). The findings suggest that the granular

Fig. 4: Small nests of granular cells are scattered around the nodule. Intracytoplasmic granules are suggested to contain lipid materials (a, H-E stain, b, LDL-apo B, c, under ultraviolet light, $\times 490$ ).

cells were neither neuroectodermal nor mesenchymal in origin, but histiocytes containing plentiful lysosomes. We thus considered this lesion as a sort of xanthomatous lesion, although we could not confirm the presence of lipids in cryosections because unfortunately all of the specimens were embedded in paraffin.

\section{Discussion}

Xanthoma is defined as a localized aggregation of tissue macrophages containing lipids. The lesion may oc- 


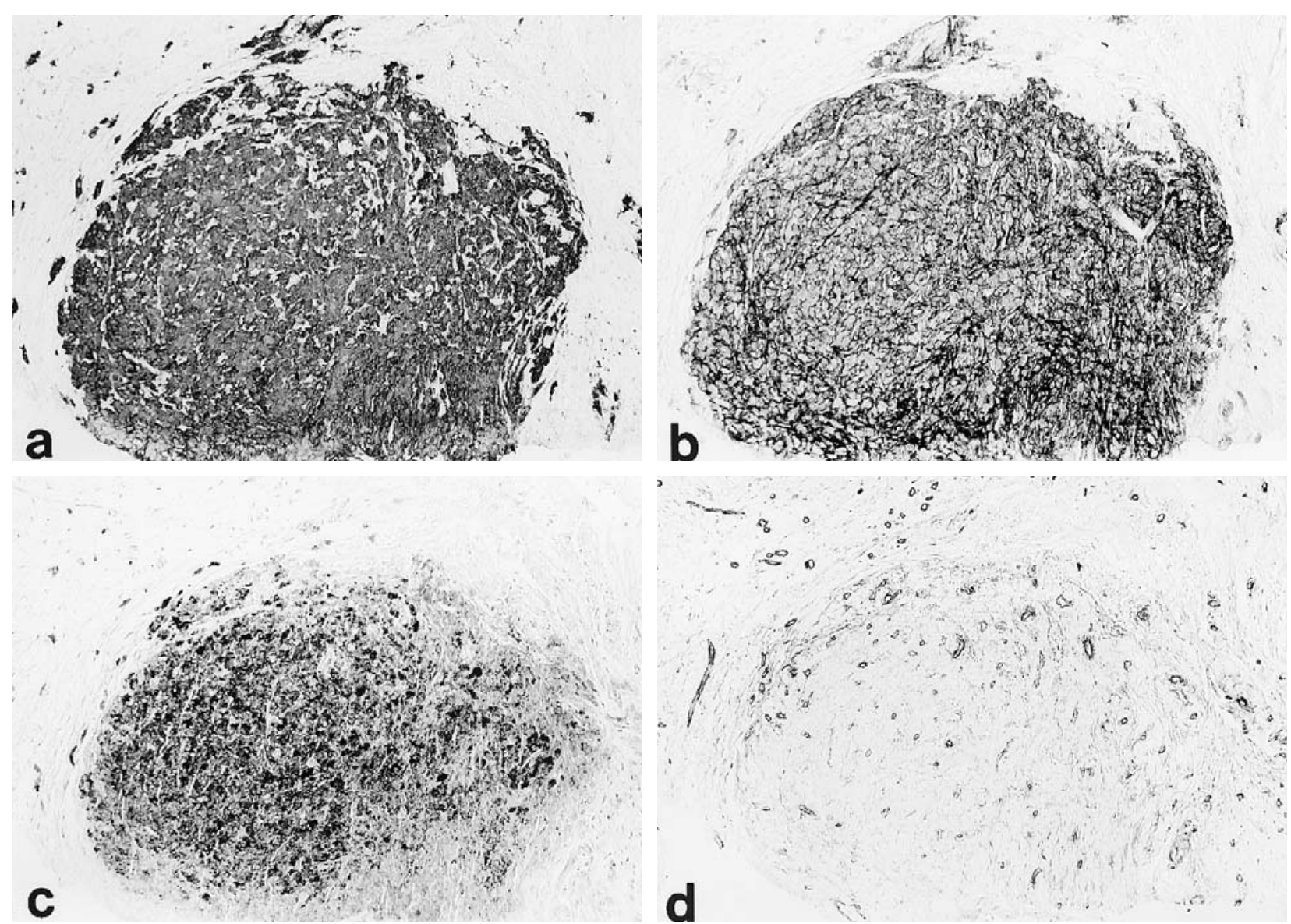

Fig. 5: Immunohistochemical stainings of granular cells for CD68 (a), HLA-DR (b), cathepsin D (c) and type IV collagen (d). The cells show finely granular stainings for CD68 and HLA-DR and coarsely granular for cathepsin D. Vascularity is rich within the nodule (ABC and PAP, hematoxylin counterstain, $\times 125)$.

cur in solitary or multiple forms, mainly in the skin $(8,9)$ and it is commonly associated with systemic disturbances of cholesterol metabolism. However, such lesions are also generated as reactive or inflammatory processes by any local stimulations. Xanthomas are rare in the oral region (10) : most of the examples of the oral mucosal xanthomas reported were associated with systemic disturbance of cholesterol metabolism (11-13) and there has been only one report of a solitary form in the gingiva without any obvious cause (14). In the present case, the patient had no systemic disorder, while he had a surgical history of an impacted supernumerary tooth extraction three years before. However, we could not determine any inflammatory effects on the left incisor tooth germ due to the surgical intervention because the operation itself did not extend to the incisor region and the right central incisor erupted without any troubles.

Since the surgical removal of the operculum could successfully accelerate the eruption of the permanent incisor tooth in our patient, we consider that the xanthomatous nodule and its overlying fibrosis are possible causes for the delay in tooth eruption. In our previous article, we did not list such a reactive lesion in the series of opercula of the teeth delayed in eruption (3). Neither did Cutright (1) and Philipsen (2) in their series. In the pericoronal hamartomas, we regard fibrosis generated between hamar- tomatous lesions and the overlying gingival mucosa, as well as the existence of hamartomas themselves, as barriers to tooth eruption. In this context, it is possible to consider that the incisor tooth was delayed in eruption due to the distinct fibrosis between the lamina propria and the submucosal myxoid tissue surrounding the xanthomatous nodules, and the presence of pericoronal mesenchymal tissues generating the xanthomatous lesion. The existence of daughter xanthomatous nodules growing around the main large one suggests that remodeling was still in progress in the pericoronal mesenchymal tissue. The volume of this particular mesenchymal tissue was not so evident when comparing the opercula with pericoronal myxofibrous hyperplasia.

Our immunohistochemical study showed that the cells consisting of xanthomatous nodules had markers for the macrophage/monocyte lineage, such as CD68 and HLA-DR, as well as such lysosomal enzymes as cathepsin D and heparanase. However, neither markers for dendritic cells, fibroblasts, nor neuro-muscular cells were demonstrated in the granular cells. Because of their granular appearance, differential diagnosis was necessary between such granular cell lesions as granular cell tumors (15-18), odontogenic granular cell tumors (15, 19, 20 ), congenital epulides (15, 16, 21, 22), epithelioid smooth muscle tumors with granular cell change (23) and 
Table 2: Immunohistochemical stainings of granular cells

\begin{tabular}{|c|c|c|c|c|c|c|}
\hline Antibody & present ca & $\mathrm{GCT}^{\left(15{ }^{18}\right)}$ & OGCT $^{(15,19,20)}$ & $\mathrm{CE}^{(15,16,21,22)}$ & $\mathrm{ESMT}^{(23)}$ & $\mathrm{OCG}^{(24)}$ \\
\hline LDL & + & & & & & \\
\hline CD68 & + & + & + & + & & \\
\hline HLA-DR & + & + & & + & & \\
\hline cathepsin D & + & & & & & \\
\hline heparanase & + & & & & & \\
\hline S-100 & - & + & - & - & - & - \\
\hline vimentin & - & + & + & + & & + \\
\hline desmin & - & & - & & + & \\
\hline myosin & - & & & & & \\
\hline
\end{tabular}

GCT: granular cell tumor

OGCT: odontogenic granular cell tumor

$\mathrm{CE}$ : congenital epulis

ESMT: epithelioid smooth muscle tumor with granular cell change

OCG: oral ceroid granuloma

oral ceroid granuloma (24). However, we could easily distinguish our xantomatous lesion from other granular cell lesions by immunohistochemical investigations as summarized in Table 2. Granular alteration in the cytoplasm is generally considered to be a degenerative response of cells, irrespective of cellular origin (25). In most of the cases, the granular appearance results from an accumulation of lysosomes. From the present immunohistochemical examination, we could conclude that the xanthomatous nodules were composed of granular histiocytes, and that a sort of xanthoma seems most likely to be its histopathologic diagnosis. It may be possible now to list xanthomatous nodules or such reactive tissue remodeling products in the pathogenic candidates for delayed tooth eruption, in addition to pericoronal hamartomatous lesions which we have already demonstrated as major causes.

\section{References}

1. Cutright DE. Histopathologic findings in third molar opercula. Oral Surg 1976; 41: 215-24.

2. Philipsen HP, Thosaporn W, Reichart PA, et al. Odontogenic lesions in opercula of permanent molars delayed in eruption. J Oral Pathol Med 1992; 21: 38-41.

3. Yonemochi H, Noda T and Saku T. Pericoronal hamartomatous lesions in the opercula of the teeth delayed in eruption: an immunohistochemical study for extracellular matrix. $J$ Oral Pathol Med 1998; 27: 441-52.

4. Toyoshima M and Nakajima M. Human heparanase. Purification, characterization, cloning, and expression. $J$ Biol Chem 1999; 274: 24153-60.

5. Saku T, Sakai H, Shibata Y, et al. An immunocytochemical study on distinct intracellular localization of cathepsin $\mathrm{E}$ and cathepsin D in human gastric cells and various rat cells. $J$ Biochem 1991; 110: 956-64.

6. Cheng J, Saku T, Okabe H, et al. Basement membranes in adenoid cystic carcinoma. An immunohistochemical study. Cancer 1992; 69: 2631-40.

7. Saku T, Yamamoto K, Miyanishi T, et al. Enhanced resolution in immunohistochemical localization of skeletal and smooth muscle myosins in human tongue. Jpn J Oral Biol 1983; 25: 592-5.
8. Fonseca E, Contreras F and Cuevas J. Papular xanthoma in children: Report and immunohistochemical study. Pediatr Dermatol 1993; 10: 139-41.

9. Bundino S, Zina AM and Aloi F. Papular xanthoma. Clinical, histological and ultrastructural study. Dermatology 1988; 177: 382-5.

10. Takagi M, Shibuya Y and Ishikawa G. Histiocytic lesions of the oral region. J Jpn Stomatol Soc 1979; 46: 43-58.

11. Raffle EJ and Hall DC. Xanthomatosis presenting with oral lesions. Br Dent $J$ 1968; 125: 62-6.

12. Brooks JK and Bltimore. Gingival and cutaneous xanthomatosis associated with primary biliary cirrhosis. Report of a case. Oral Surg Oral Med Oral Pathol 1990; 70: 744-7.

13. Caputo R, Veraldi S, Grimalt R, et al. The various clinical patterns of xanthoma disseminatum. Considerations on seven cases and review of the literature. Dermatology 1995; 190: $19-24$.

14. Chaudhry AP and Gorlin RJ. A solitary xanthoma of the attached gingiva-Report of a case. Oral Surg Oral Med Oral Pathol 1960; 13: 449-51.

15. Mirchandani R, Sciubba JJ and Mir R. Granular cell lesions of the jaws and oral cavity: A clinicopathologic, immunohistochemical, and ultrastructural study. J Oral Maxillofac Surg 1989; 47: 1248-55.

16. Regezi JA, Zarbo RJ, Courtney RM, et al. Immunoreactivity of granular cell lesions of skin, mucosa, and jaw. Cancer 1989; 64: 1455-60.

17. Chen SY. Central granular cell tumor of the jaw: An electron microscopic and immunohistochemical study. Oral Surg Oral Med Oral Pathol 1991; 72: 75-81.

18. Kurtin PJ and Bonin DM. Immunohistochemical demonstration of the lysosome-associated glycoprotein CD68 (KP-1) in granular cell tumors and schwannomas. Hum Pathol 1994; 25: $1172-8$.

19. Shiro BC, Jacoway JR, Mirmiran SA, et al. Central odontogenic fibroma, granular cell variant. A case report with S-100 immunohistochemistry and a review of the literature. Oral Surg Oral Med Oral Pathol 1989; 67: 725-30.

20. Yih W-Y, Thompson C, Meshul CK, et al. Central odontogenic granular cell tumor of the jaw: Report of case and immunohistochemical and electron microscopic study. J Oral Maxillofac Surg 1995; 53: 453-9. 
21. Zuker RM and Buenechea R. Congenital epulis: Review of the literature and case report. J Oral Maxillofac Surg 1993; 51: $1040-3$.

22. Lack EE, Worsham GF, Callihan MD, et al. Gingival granular cell tumors of the newborn (congenital epulis). A clinical and pathologic study of 21 patients. Am J Surg Pathol 1981; 5: $37-46$.

23. Mentzel T, Wadden C and Fletcher CDM. Granular cell change in smooth muscle tumours of skin and soft tissue.
Histopathology 1994; 24: 223-31.

24. Triantafyllou A. Cytological and cytochemical investigations on granular cells in oral lichen planus. J Oral Pathol Med 1996; 25: 350-5.

25. Sobel HJ, Avrin E, Marquet E, et al. Reactive granular cells in sites of trauma: A cytochemical and ultrastructural study. Am J Clin Pathol 1974; 61: 223-34.

(Accepted for publication November 12, 1999) 